\title{
Telediagnosis of transbronchial fine needle aspirations - a feasibility study
}

\author{
K. Kayser ${ }^{\mathrm{a}, *}$, G. Kayser ${ }^{\mathrm{a}}$, H.D. Becker ${ }^{\mathrm{b}}$ and \\ F. Herth ${ }^{\mathrm{b}}$
}

a Department of Pathology, Thoraxklinik, Heidelberg, Germany

${ }^{\mathrm{b}}$ Department of Endoscopy, Thoraxklinik, Heidelberg, Germany

Aim: To analyze the diagnostic accuracy of telediagnostic procedures for transbronchial fine needle aspirations. Material and methods: A double blind study was performed on cytological slides of 54 randomly selected cases with transbronchial fine needle aspirations. The slides were digitized using a Leica digital camera DC100 mounted on a microscope Leica Laborlux S, and analyzed by an experienced pathologist without knowing the definite diagnosis or any additional clinical data. The diagnoses stated by analyzing the digital images were compared to the final conventional diagnoses. In addition, the duration of the digital diagnosis, used magnifications, and difficulties for correct sampling were documented. Results: The "digital" diagnoses of the 54 cases were all in general agreement with the definite diagnoses. No wrong positive or wrong negative case in respect to malignant/non-malignant (31/23) or to small cell/non-small cell $(9 / 22)$ occurred. The performance of a digital diagnosis lasted for $115 \mathrm{~s}$ at average (15-260 s), and is significantly longer compared to that of conventional fine needle aspiration judgement $(20 \mathrm{~s})$. The screening magnification was commonly set to $\times 2.5$, that for definite diagnostic analysis $\times 40$. Benign diseases ( 2 tuberculosis and 3 sarcoidosis cases) were correctly classified. Conclusions: Telepathology systems can probably be used for fine needle aspiration analysis without major diagnostic errors. Their use can improve the endoscopic sampling and avoid second anesthesia when missing the lesion of request during the first examination.

Keywords: Fine needle aspiration, lung, telepathology, feasibility study

\footnotetext{
*Corresponding author: Klaus Kayser, MD, PhD, Department of Pathology, Thoraxklinik, Amalienstr. 5, D-69126 Heidelberg, Germany. Tel.: +496221 396496; Fax: +496221 396238; E-mail: klkayser@lung.de.
}

\section{Introduction}

Diagnostic telepathology is now-a-days an established diagnostic technique, and includes all diagnostic aspects in pathology $[2-7,16,17,22]$. The electronic transfer and the quality of transferred images permit a diagnostic work at electronic display stations which is comparable to viewing histopathological and cytological images at a microscope [8-10,14,16,18,28]. From the basic point of view, two different application modes can be distinguished, namely I interactive or on-line diagnostic work between at least two work stations, and II passive or off-line procedures when both work stations are active independently from each other [16,27, 29-31]. Application mode I is the basic procedure for on-line distant diagnosis, and is mainly performed for intra-operative frozen section services. It requires fast line connections, and the transfer of an overview image with subsequent high resolution images, or a remote control microscope. Application mode II is mainly used for expert consultation services, often in an Internet data transfer mode [12,16,19-21,30]. It does not require a transfer of huge amount of image data, and can be performed with a quite small number of still images if the selection of diagnostic important images is guarantied [23,24]. A more detailed analysis of both application modes comes to the conclusion that the key problem in telepathology is related to the bias of image selection, i.e., to assure that especially those image compartments are transferred which are diagnostic relevant. To assure a transfer of these image compartments an adequate sampling technique is necessary, in other words, a stratified sampling [11]. This procedure basically requires sophisticated knowledge of the information procedure, i.e., diagnostic knowledge of pathology [11]. This is the major constraint of an appropriate use of telecytology. The search for atypical cells in cytological smears is combined with an overload of normal cells, and usually less than $1 \%$ of all cells present are those with diagnostic information [1]. In contrast to common cytological smears fine needle aspirations are not overloaded with normal cells, 
and the rate of tumor cells within the total of aspirated cells might even reach $80-100 \%$. Thus, the diagnostic judgement of fine needle aspirations does not require a detailed and sophisticated sampling technique. In addition, it is based upon a simple and easy to perform tissue preparation and staining procedure, which is not comparable to the high sophisticated sampling and tissue preparation technique in frozen section services. Fine needle aspiration telecytology fulfills all basic aspects to be applied in an on-line or interactive telecytology: The handling in the surgical (endoscopy) theater is simple and fast, and the diagnosis at the pathologist's side is not handicapped with difficult or time-requiring screening or sampling procedures. This study has been performed to analyze and simulate on-line telecytology with bronchial fine needle aspirations in order to collect some basic data and parameters for implementation this technique into patient oriented work.

\section{Material and methods}

This double-blind study was uses non-selected transbronchial fine needle aspirations performed in the Department of Endoscopy of the Thoraxklinik, Heidelberg, and analyzed in the Department of Pathology, Thoraxklinik, Heidelberg from March 1, 2000-
May 30, 2000. All cytological specimens seen during this period were included in the study, i.e., no selection criteria were applied. The slides were digitized using a Leica digital camera DC100 mounted on a microscope Leica Laborlux S. The screening procedure of the slides was performed in the black-and-white mode of the camera due to easier focus and shorter image acquisition time. A low magnification objective $(\times 2.5)$ was used for screening, followed by a $\times 10$ objective for first and a $\times 20$ objective for second analysis of the cells. The diagnostic important areas were then transferred into the color display and analyzed by an experienced pathologist without knowing the final diagnosis or any clinical data of the patient using a $\times 40$ objective. The telecytological diagnosis was then compared to the final conventional diagnosis, and the definite histological diagnosis, if available. In addition, the duration of the digital diagnostic procedure, the used magnification, the number of analyzed images, and potential difficulties for correct sampling were documented. A total of 54 patients was included in the study.

\section{Results}

Synopsis of material is given in Table 1. A total of 38 men and 16 women was included in the study.

Table 1

Synopsis of material

\begin{tabular}{lccc}
\hline Feature & Men $(N=38)$ & Women $(N=16)$ & Total $(N=54)$ \\
\hline Age (years, min-max) & $34-80$ & $34-80$ & $34-80$ \\
Fine needle aspiration through & & & \\
$\quad$ trachea & 10 & 4 & $14(26 \%)$ \\
main bronchus & 15 & 6 & $21(39 \%)$ \\
stem bronchus & 13 & 6 & $19(35 \%)$ \\
\hline
\end{tabular}

Table 2

Confirmation of fine needle aspiration diagnosis (telecytology) by final conventional diagnosis (if both bronchial biopsy and an operation was performed, only the diagnosis of the surgical specimen is stated)

\begin{tabular}{lccc}
\hline Lesion & Fine needle telecytology & Bronchial biopsy & Surgical specimen \\
\hline Malignant & 31 & 19 & 12 \\
small cell lung cancer & 9 & 9 & 0 \\
non-small cell lung cancer & 22 & 8 & 14 \\
epidermoid & 10 & 5 & 7 \\
adenocarcinoma & 12 & 3 & 5 \\
large cell anaplastic & 0 & 0 & 2 \\
Benign lesion & 23 & 22 & 2 \\
inflammation & 18 & 18 & 0 \\
epithelioid cells (tuberculosis) & 5 & 0 & 2 \\
(sarcoidosis) & & 3 & 0
\end{tabular}


Table 3

Duration and objectives used in telecytology simulation

\begin{tabular}{lcc}
\hline Procedure & Objective & Duration (mean, in seconds) \\
\hline Overview screening & $\times 2.5$ & 70 \\
First judgement & $\times 10$ & 25 \\
Second look & $\times 20$ & 10 \\
Definite diagnosis & $\times 40$ & 10 \\
Total & & 115 \\
\hline
\end{tabular}

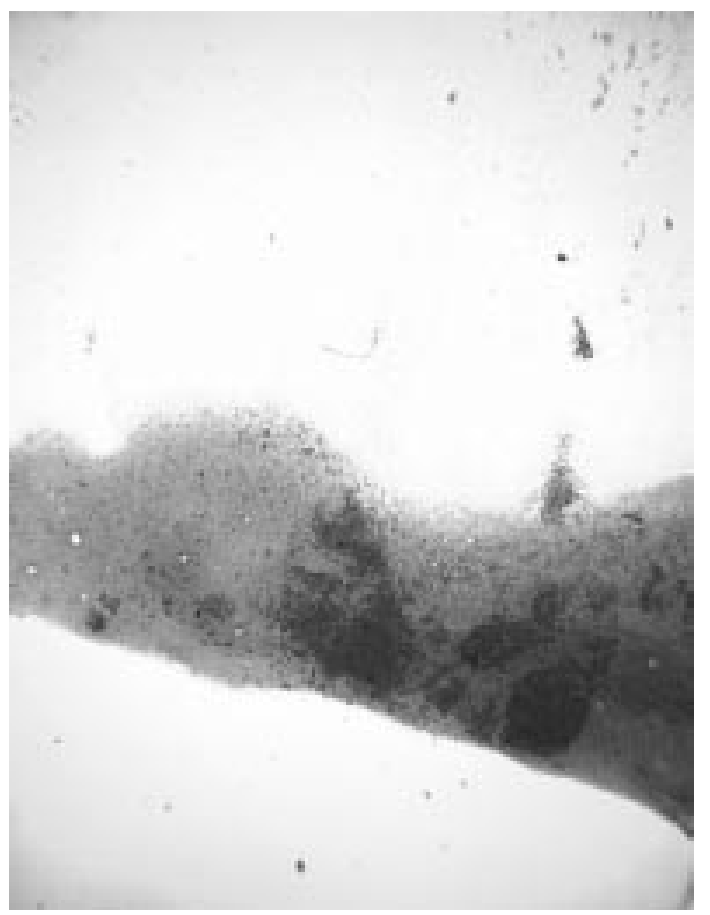

Fig. 1. Black-and-white image at low magnification $(\times 10)$ used for cellular screening.

\section{gray value distribution}

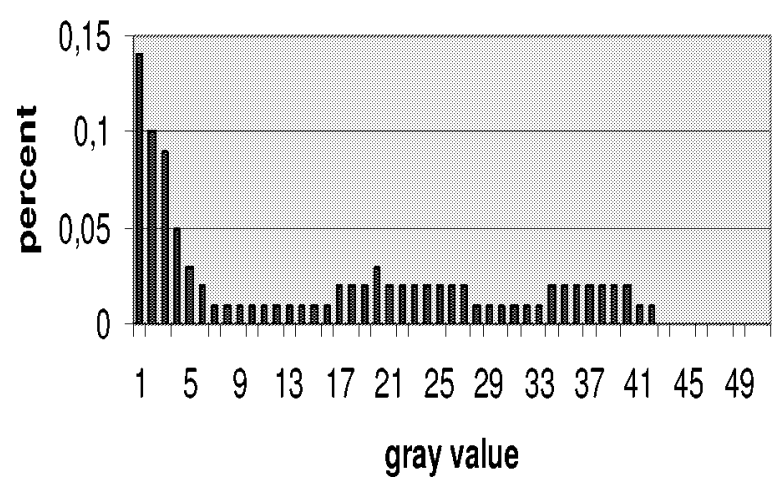

Fig. 2. Gray value distribution of a screening image at low magnification (obtained from Fig. 1).
The sex distribution, mean age and the frequency distribution of the diagnoses do not differ from the basic patients collective of the Thoraxklinik. The association of the telecytology diagnosis with the final cytology report is given in Table 2 . No wrong positive or wrong negative telecytology report occurred in respect to malignant/non-malignant diagnosis or small cell/non-small cell carcinoma. By telecytology, adenocarcinoma were stated in two cases in contrast to the definite diagnosis of an epidermoid carcinoma. This error is, however, only of minor therapeutic influence. The telecytology diagnostic period (115 s, see Table 3 ) is considerably longer compared to that of conventional diagnostic procedure (measured to $20 \mathrm{~s}$ ). The screening procedure at the video screen was mainly performed with an objective $\times 2.5$ in contrast to screening at the microscope $(\times 10$ or $\times 20)$; that for the definite diagnosis was $\times 40$ in both techniques. The screening with black-and-white images at low magnification as shown in Fig. 1 cannot be judged on spatial resolution and is mainly based upon gray value distribution which is shown in Fig. 2. The diagnostic important area as selected to the lower threshold of the gray value distribution is shown in Fig. 3. The final digitized image of the same case showing atypical cells consistent with a small cell anaplastic carcinoma are presented in Fig. 4. The nature of the atypical cells can be judged without any major difficulties.

\section{Discussion}

On-line telepathology to be applied in frozen section service has now been established in several institutes of pathology [16,19-21,25,26]. The technical and diagnostic aspects have been discussed by several authors, and it can be agreed that the diagnostic accuracy is somewhat lower, however comparable to conventional frozen section service $[3,13,21$, 25]. The major constraints of telepathology frozen section services are the long duration for assessment of intra-operative diagnosis which has been reported to about $30 \mathrm{~min}$ at average [1,9,21,25], and difficulties to maintain high technical standards in slide preparation over a long period of time [12]. Basically, telecytology does not require difficult tissue preparations or specialized personnel. The preparation of diagnostic adequate smears is by no means comparable to that of working with a cryostat, and can be done in a few minutes. The major constraint is the screening of the slide and the rare diagnostic events. Cytology diag- 


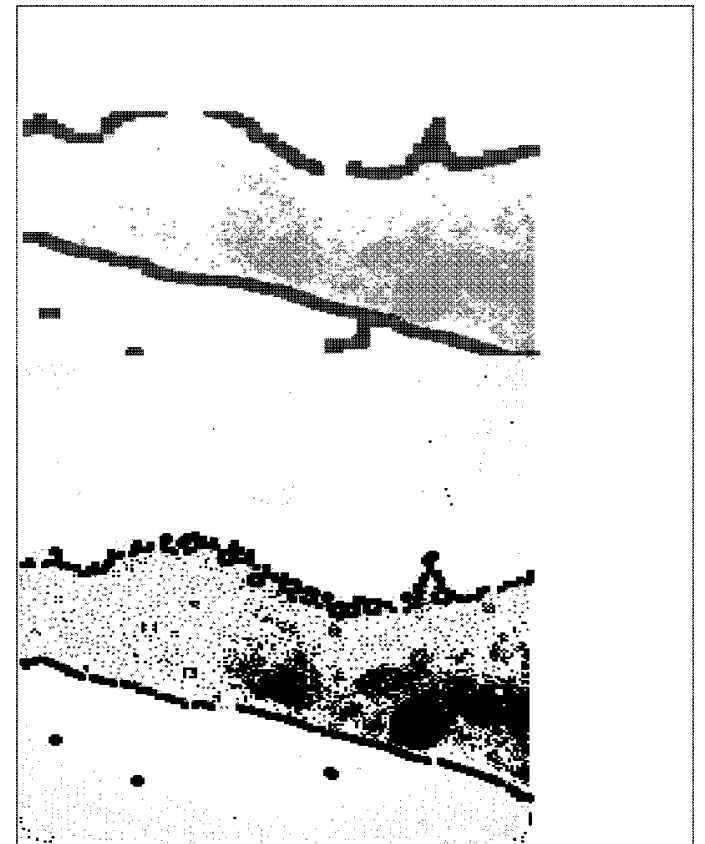

(a)

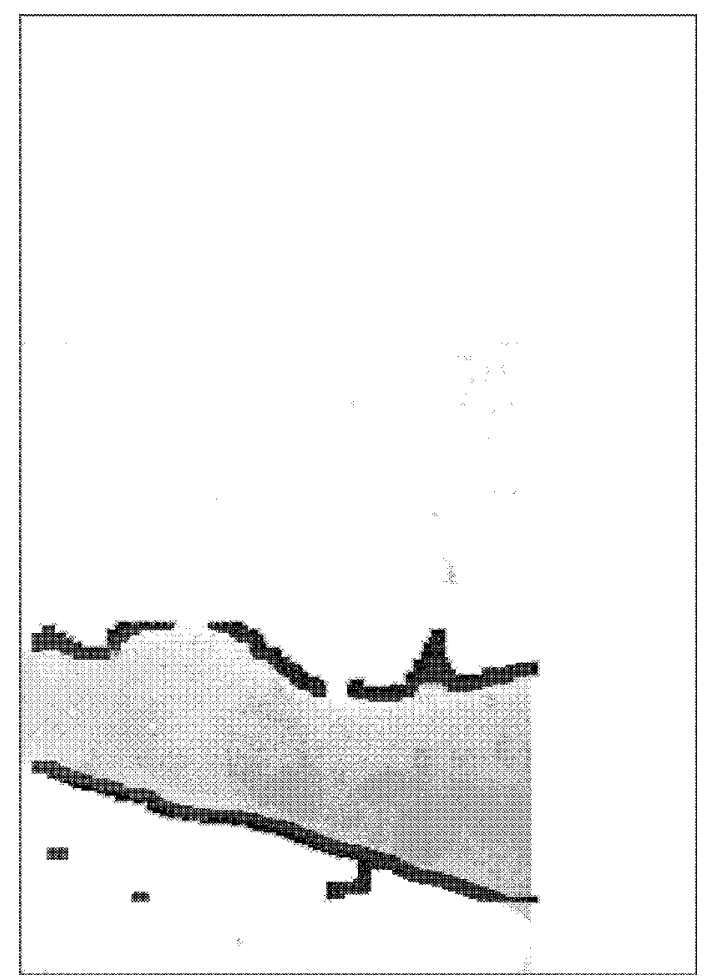

(b)

Fig. 3. Selection of diagnostic important area by gray value thresholds. The upper compartment displays the boundary and the density of atypical cells, the lower one the calculated center (in green color) of a potential automated sampling procedure.

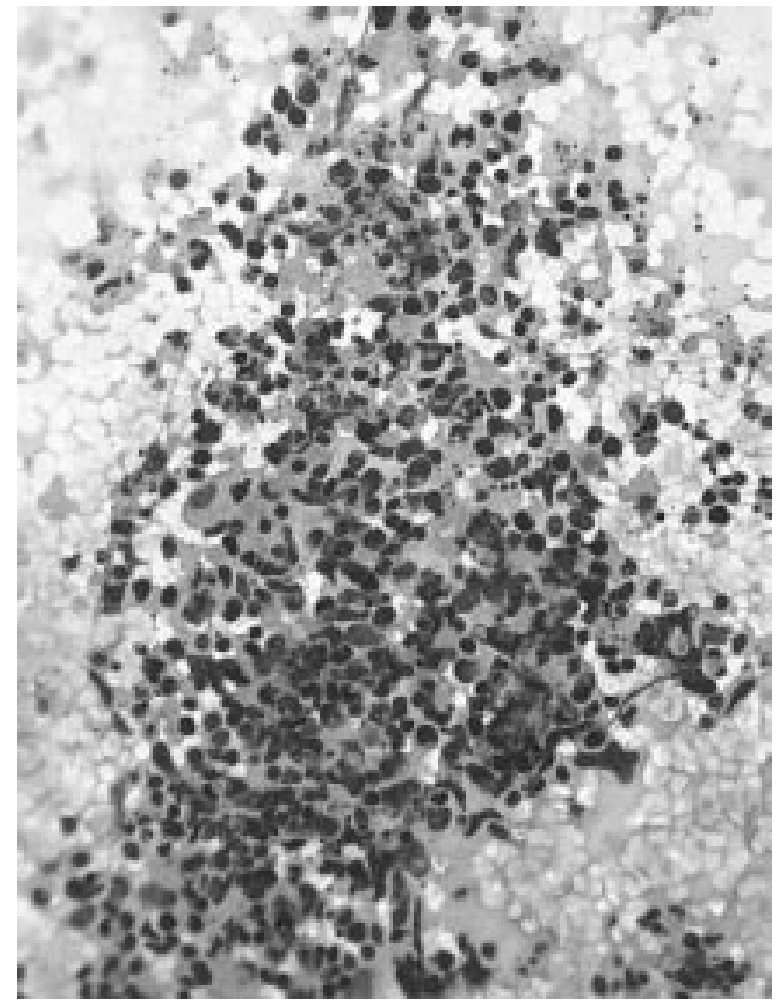

Fig. 4. High resolution image $(\times 40)$ used for telecytology diagnosis (small cell lung carcinoma, the same case as shown in Fig. 1).

nosis requires high magnification in contrast to histological diagnosis, telecytology is handicapped by continuously transfer of high and low resolution images. Fine needle aspiration is a medical technique which avoids the principal constraint of cytology. It is based upon aspiration of cells which are present at the place of the lesion, and possesses a high sensitivity. Transbronchial, ultrasound-guided fine needle aspiration is especially useful for lesions suspicious for diseases involving intra-pulmonary lymph nodes and tumors with preferable submucosal growth such as adenocarcinomas and small cell lung cancer.

This feasibility study clearly demonstrates the principle application of on-line telediagnosis in transbronchial fine needle aspirations. No major diagnostic errors occurred. The duration of the total diagnostic procedure is short enough to permit new tissue sampling if adequate sampling of diagnostic appropriate cells failed. Using a more appropriate image acquisition camera based upon video standard with color live images the slide screening procedure can be improved interactively. On the other hand, our study indicates that screening of cytological slides can be performed automatically by simple gray value analysis at low 
magnification. These data reflect to results published on histological images at low magnification [15]. Simple gray value analysis does not permit a detailed diagnosis either in cytology or in histology; however, it permits the detection of areas of potential diagnostic importance [15]. In summary, this feasibility study confirms the theoretical consideration on potential use of inter-active telecytology procedures for transbronchial fine needle aspirations, which can probable combined with automated sampling procedures.

\section{Acknowledgement}

The generous financial support of the Dr. M. Scheel Stiftung fuer Krebsforschung and of the Verein zur Foerderung des biologisch-technologischen Fortschritts in der Medizin e.V. is gratefully acknowledged.

\section{References}

[1] M.M. Borst, G. Koloczek, H.D. Becker and K. Kayser, Quality control study of bronchoscopic biopsies and cytology smears - results of a double blind study, Elec. J. Pathol. Histol. 5(3) (1999), No. 993-04.

[2] Ch. Busch and S. Olsson, Future strategy for telepathology trial in Sweden: higher resolution, real time transmission in a multipurpose work station for diagnostic pathology, Arch. Anat. Cytol. Pathol. 43 (1995), 242-245.

[3] T.J. Eide, I. Nordrum and H. Stalsberg, The validity of frozen section diagnosis based on video-microscopy, Zentralbl. Pathol. 138 (1992), 381-436.

[4] L.Goncalves and C. Cunha, Telepathology experiences in Portugal, Elec. J. Pathol. Histol. 1(4) (1995), No. 954-09.

[5] G. Haroske, A. Boecking, W. Meyer, K. Kayser, D. Kunze and M. Oberholzer, EUROQUANT - a quantitation server for remote DNA image cytometry, Elec. J. Pathol. Histol. 3(4) (1997), No. 974-08.

[6] B.A. Harris, Jr., Telemedicine: a glance into the future (editorial; comment), Mayo Clin. Proc. 69 (1994), 1212.

[7] K. Kayser, Telepathology in Europe. Its practical use, Arch. Anat. Cytol. Pathol. 43 (1995), 196-199.

[8] K. Kayser, Telemedizin, Wiener Klin. Wschr. 108 (1996), 932940.

[9] K. Kayser, M. Drlicek and W. Rahn, Aids of telepathology in intraoperative histomorphological tumor diagnosis and classification, In vivo 7 (1993), 379-382.

[10] K. Kayser, P. Fritz and M. Drlicek, Aspects of telepathology in routinary diagnostic work with specific emphasis on ISDN, Arch. Anat. Cytol. Pathol. 43 (1995), 216-218.

[11] K. Kayser, P. Hufnagl, G. Kayser and S. Zink, Stratified sampling: Basic ideas and its application in pathology, Elec. J. Pathol. Histol. 5(4) (1999), No. 994-06.
[12] K. Kayser and C. Kayser, Telepathology - aspects of social influence and quality control, Elec. J. Pathol. Histol. 2 (1996), No. 963-04.

[13] K. Kayser, M. Oberholzer, G. Weisse, I. Weisse and H. Eberstein v, Long distance image transfer: First results for its use in histopathological diagnosis, Acta Pathol. Microbiol. Immunol. Scand. 99 (1991), 808-814.

[14] K. Kayser and M. Drlicek, Visual telecommunication for expert consultation of intraoperative sections, Zentralbl. Pathol. 138 (1992), 381-436.

[15] K. Kayser, H. Stute and M. Noetzel, Simulation der histopathologischen Diagnostik mit Hilfe eines automatischen Bildanalysesystems (Visiac), Gegenbaurs morphol. Jahrb. 135 (1989), 19-24.

[16] K. Kayser, J. Szymas and R.N. Weinstein, Telepathology: Telecommunication, Electronic Education and Publication in Pathology, Springer, Berlin, New York, 1999.

[17] E. Martin, P. Dusserre, C. Got, A. Vieillefond, B. Franc, G. Brugal and B. Retailliau, Telepathology in France. Justifications and developments, Arch. Anat. Cytol. Pathol. 43 (1995), 191-195.

[18] I. Nordum, B. Engum, E. Rinde, A. Finseth, H. Ericsson, M. Kearney, H. Stalsberg and T.J. Eide, Remote frozen section service: a telepathology project in northern Norway, Hum. Pathol. 22 (1991), 514-518.

[19] B. Nymo and B. Engum, Telemedicine to improve the quality, availability and effectiveness of the health service in rural regions, Kjeller, TF-lecture F10/90, 1990, Norwegian Telecom research.

[20] M. Oberholzer, H.R. Fischer, H. Christen, S. Gerber, M. Bruehlmann, M. Famos, C.H. Winkler, P. Fehr and L. Baechtold, Telepathology with an Integrated Services Digital Network: a new tool in pathology, in: Compendium on the Computerized Cytology and Histology Laboratory, G.L. Wied, P. Bartels, D. Rosenthal and U. Schenck, eds, Tutorials of Cytology, Chicago, 1994, pp. 295-305.

[21] M. Oberholzer, H.R. Fischer, H. Christen, S. Gerber, M. Bruehlmann, M. Mihatsch, M. Famos, C. Winkler, P. Fehr, L. Baechtold and K. Kayser, Telepathology with ISDN - A new tool for image transfer in surgical pathology, Hum. Pathol. 24 (1993), 1078-1085.

[22] M. Oberholzer, H.R. Fischer, H. Christen, S. Gerber, M. Bruehlmann, M.J. Mihatsch, T. Gahm, M. Famos, C. Winkler, P. Fehr, H.J. Hosch and L. Baechtold, Telepathology: frozen section diagnosis at a distance, Virchows Arch. 426 (1995), 3-9.

[23] S. Olsson and Ch. Busch, A national telepathology in Sweden. Feasibility and assessment, Arch. Anat. Cytol. Pathol. 43 (1995), 234-241.

[24] P. Schwarzmann, J. Schmid, C.I. Schnoerr, G. Straessle and S. Witte, Telemicroscopy stations for telepathology based on broadband and ISDN connections, Arch. Anat. Cytol. Pathol. 43 (1995), 209-215.

[25] P. Schwarzmann, Telemicroscopy. Design considerations for a key tool in telepathology, Zentralbl. Pathol. 138 (1992), 381436.

[26] G. Stauch, K.W. Schweppe and M. Puetz, One year experience with telepathology for frozen sections, Elec. J. Pathol. Histol. 1(4) (1995), No. 954-08. 
[27] A. Vieillefond, F. Staroz, M. Fabre, P. Bedossa, V. Martin-Pop, E. Martin, C. Got and B. Franc, Reliability of the anatomopathological diagnosis by static image transfer, Arch. Anat. Cytol. Pathol. 43 (1995), 246-250.

[28] R.S. Weinstein, Prospects for telepathology, Human Pathol. 17, 433-434.

[29] R.S. Weinstein, A. Bhattacharyya, Y.P. Yu, J.R. Davis, J.M. Byers, A.R. Graham and R. Martinez, (1995) Pathology consultation services via the Arizona-International telemedicine network, Arch. Anat. Cytol. Pathol. 43 (1986), 219-226.
[30] R.S. Weinstein, K.J. Bloom, E.A. Krupinski and L.S. Rozek, Human performance studies of the video microscopy component of a dynamic telepathology system, Zentralbl. Pathol. 138 (1992), 381-436.

[31] R.S. Weinstein, K.J. Bloom and L.S. Rozek, Static and dynamic imaging in pathology, in: Image Management and Communications in Patient Care: Implementation and Impact, S.K. Mun, M. Greberman, W.R. Hendee and R. Shannon, eds, IEEE Computer Soc. Press, Los Alamitos, CA, 1990, pp. $77-$ 85. 


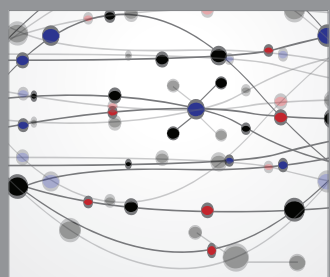

The Scientific World Journal
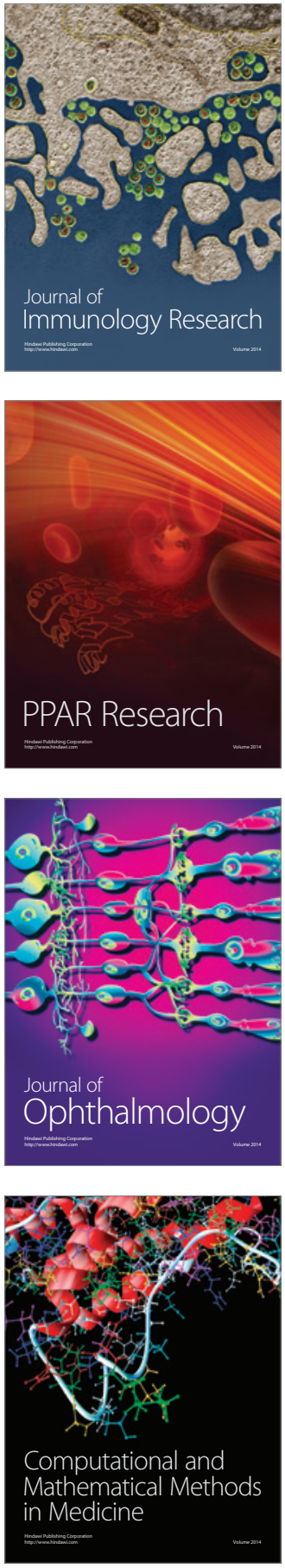

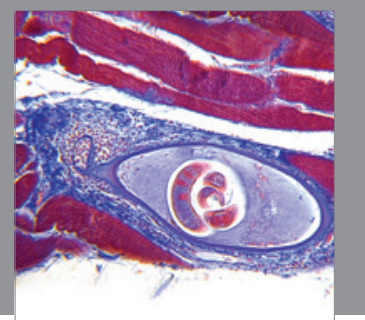

Gastroenterology

Research and Practice
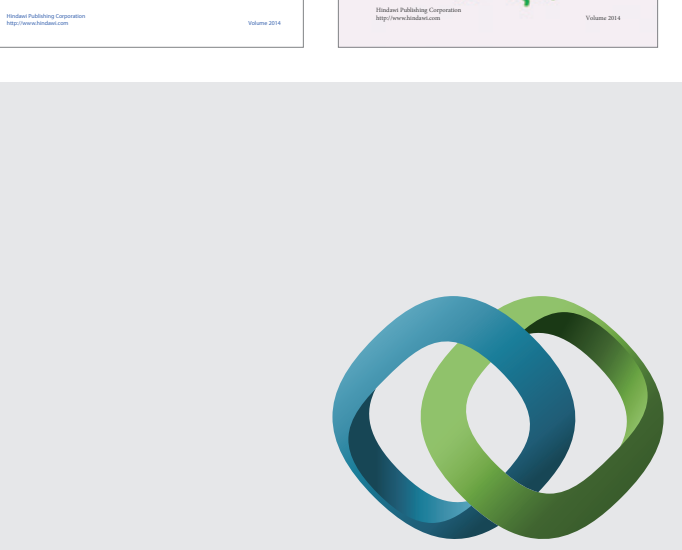

\section{Hindawi}

Submit your manuscripts at

http://www.hindawi.com
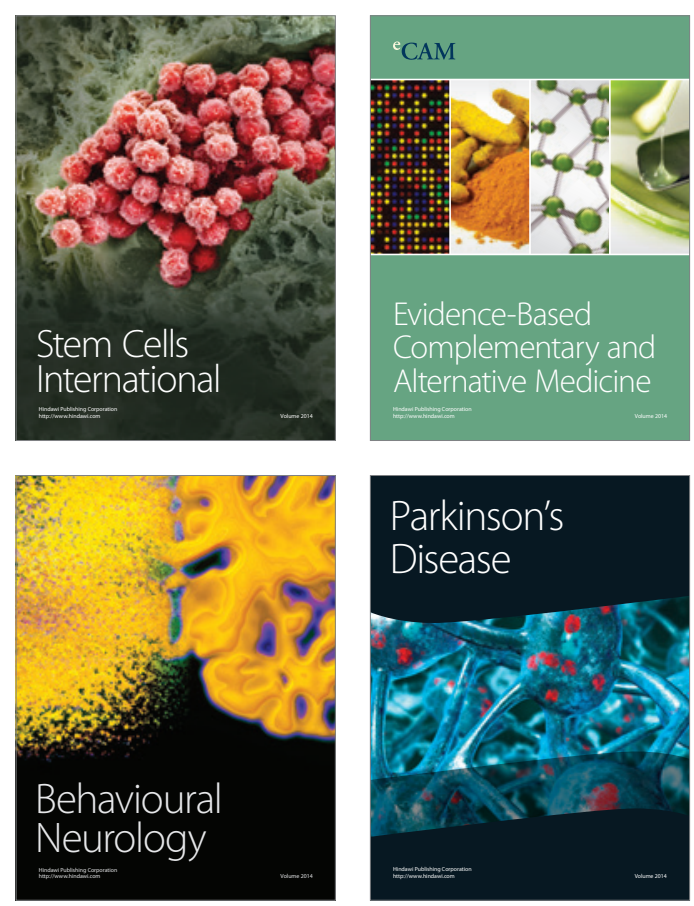

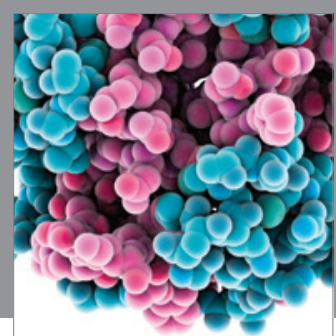

Journal of
Diabetes Research

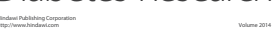

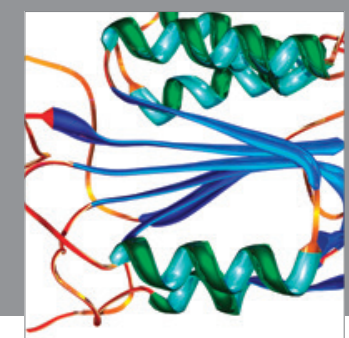

Disease Markers
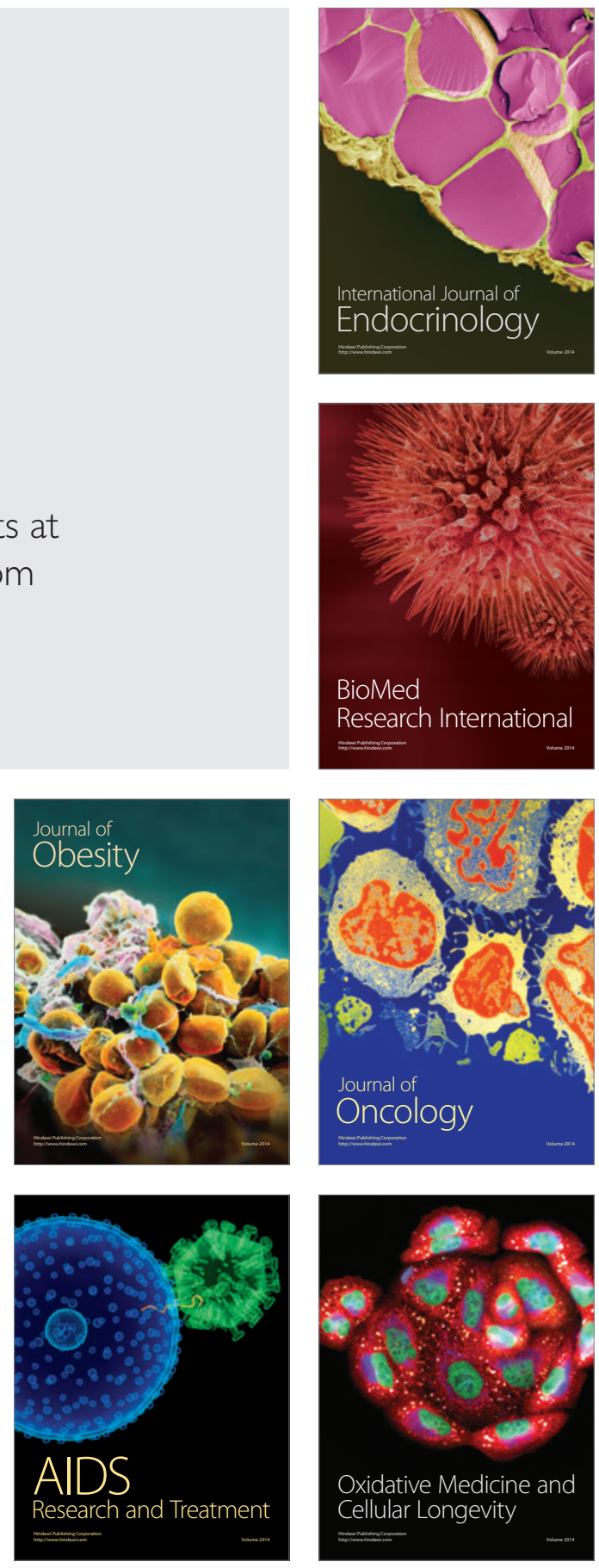